\section{(6) OPEN ACCESS}

\title{
The prevalence, variety and impact of wrist problems in elite professional golfers on the European Tour
}

\author{
Roger Hawkes, ${ }^{1}$ Phil O'Connor, ${ }^{2}$ Doug Campbell ${ }^{3}$
}

\begin{abstract}
${ }^{1}$ European Tour Performance Institute, European Tour, Virginia Water, Surrey, UK ${ }^{2}$ Leeds Musculoskeletal Biomedical Research Unit (LMBRU), Department of Radiology, Leeds Teaching Hospitals NHS Trust, Leeds, UK ${ }^{3}$ Department of Orthopaedic Surgery, Leeds Teaching Hospitals NHS Trust, Leeds, UK
\end{abstract}

\section{Correspondence to}

Dr Roger Hawkes

MB FFSEM (Ire) (UK),

73 Wigginton Road,

Tamworth, Staffordshire B79

8RN, UK; RAH@wkes.co.uk

Received 25 October 2012 Revised 2 August 2013 Accepted 11 August 2013

Published Online First

6 September 2013

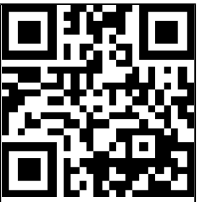

Open Access Scan to access mor free content

\section{SLinked}

- http://dx.doi.org/10.1136/ bjsports-2013-093010

To cite: Hawkes $R$,

O'Connor P, Campbell D. Br J Sports Med

2013;47:1075-1079.

\begin{abstract}
Objectives Golf is a popular sport played by an estimated 57 million people. Previous studies on wrist injuries in elite golfers have been of simple design and have demonstrated such injuries to be frequent, although no studies report the incidence, variety, severity or impact on the activity of wrist injuries in detail. This prospective cross-sectional study assesses these factors in a cohort of elite professional golfers.

Methods European Tour golfers eligible to compete at the 2009 BMW PGA Championship at Wentworth were studied. Study design involved the completion of a structured questionnaire supplemented by interview and examination when required, with performance statistics provided by the European Tour. The severity of injury was assessed by the number of missed tournaments and the amount of time of missed practice.
\end{abstract}

Results 128 of 153 eligible golfers, (84\%) completed the study with 38 golfers (30\%) reporting 43 problems. The majority of injuries $(67 \%)$ occurred in the leading wrist at the most common location, the ulnar side of the wrist (35\%). $87 \%$ of all ulnar-sided and $100 \%$ of radial-sided problems were in the leading wrist.

Conclusions There were clear side differences reported by the players with the lead wrist demonstrating much higher injury rates in all areas. The most significant injury, in terms of absence from competition, was extensor carpi ulnaris tendon subluxation. Specific injuries are explained in relation to the biomechanics of the golf swing. Most structural injuries have a specific treatment and rehabilitation plan, which can involve significant periods of time away from the sport, while the management of many of the more minor problems is through alterations in technique or practice regimes, aiming to keep a golfer playing during recovery.

\section{INTRODUCTION}

Golf is one of the most popular global sports with an estimated 57 million participants worldwide (4 million in the UK). ${ }^{1}$ It has a well-organised, well-funded and highly competitive professional circuit which is composed of different tours based on the geographical location of tournaments. A player on the European Tour will play an average of 25 tournaments/year and each tournament will typically consist of 72 holes of golf, 18 holes/day for 4 days. Gosheger et $a l^{2}$ reported that a typical golf professional in Germany will hit 200 balls in practice and play four rounds of 18 holes every week.

In spite of the popularity of the sport, the injury rates in golf have been poorly researched. Previous questionnaire-based studies have shown that amateur $^{34}$ as well as professional golfers ${ }^{2}$ experience injuries but that these are infrequent. Male professional golfers reported an average of two injuries in a career, each resulting in 9.3 weeks' absence from the Tour, and the injuries were most common in those players hitting more than 200 balls in practice every week. ${ }^{2}$ This study aims to document the type, severity and incidence of wrist and hand injuries that occur in elite golfers competing on the European Tour.

By understanding the nature of these injuries, their likely aetiology and their impact on practice and tournament play, we aim to improve the recognition, management and outcome of wrist injuries to benefit the players, their coaches and the health professionals responsible for elite golfers.

\section{MATERIALS AND METHODS}

This study used a structured questionnaire and, where appropriate, a clinical examination of the wrist and hand was performed by a single observer over a 6-month period. A cohort of 153 elite golfers competing in the 2009 BMW PGA Championship at Wentworth or who were injured at the time of the tournament, but who would have been eligible to play, were included in the study. We collected standard demographic information, details of previous wrist injuries, the mechanism of injury, any investigations or treatment carried out, time off play and the current wrist health status. An injury was defined as any medical problem affecting the wrist that was incurred during practice or competition and required medical attention. Each golfer was asked if the condition was ongoing or whether it had resolved.

Finally, performance statistics were obtained from the official European Tour for each golfer (measured during the previous season) to ascertain whether symptoms correlated with selected performance characteristics-driving distance (a measure of power), 'greens in regulation' (a measure of accuracy). It could have been that players who drove the ball further or those who were more accurate may have been putting more force through their wrists, and as a consequence may be expected to have more wrist injuries.

A Student $\mathrm{t}$ test in Microsoft excel was used to determine statistical significance when comparing 
the injured and uninjured groups. Statistical significance was accepted as any $\mathrm{p}$ value $<0.05$.

\section{RESULTS}

\section{Demographics}

Out of a possible 153 questionnaires, 128 were completed (response rate of $84 \%$ ) by golfers (all men) with a mean age of $33.3 \pm 6.3$ years $(20-49$ years). There was no significant difference between the mean age of the injured and uninjured groups $(34.1 \pm 6.9$ years vs $33.0 \pm 6.1$ years, $p=0.4)$.

Thirty-eight golfers (30\% of respondents) reported 43 previous wrist problems and 25 of the symptomatic group (20\% of respondents) missed more than one tournament or had a reduced practice of more than 1 month. Fourteen of the 38 golfers reporting previous injuries (11\% of respondents) had ongoing related problems at the time of the interview.

There was no statistical difference in 'playing years' between the symptomatic group (mean $=11.9 \pm 6.1$ years on tour) and the asymptomatic group (mean $=11.7 \pm 6.9$ years on tour; $p=0.9$ ).

Likewise, there was no statistical difference in performance as measured by comparing driving distances (injured $=286 \pm 11$ yards vs uninjured $=284 \pm 8$ yards, $\mathrm{p}=0.5$ ) and accuracy from tee to green (both groups hit the greens in $69 \%$ of regulation $(\mathrm{p}=0.9))$.

\section{Clinical problems}

The majority of wrist problems (29-67\% of all problems) involved the leading wrist. Two golfers described identical problems in both wrists and 12 golfers (28\%) had a problem in the non-leading wrist. Symptoms were described in a variety of anatomical locations.

\section{Ulnar-sided problems}

Causes of pain in this group (table 1) comprised extensor carpi ulnaris (ECU) tendinosis (8 cases), ECU subluxation (4 cases), ulnar pain after hitting a 'fat' shot (where too much turf is taken while playing a shot) ( 2 cases, and unidentified ulnar pain possibly due to a problem in triangular fibrocartilage complex (TFCC) (1 case).

There were eight cases of ECU tenosynovitis in seven golfers. Only one case was in the non-leading wrist, one case was bilateral and the other five cases were in the leading wrist. Three golfers attributed their problem to playing off hard ground, one golfer attributed the injury to the use of mats and one identified

Table 1 Ulnar wrist pain

\begin{tabular}{llll}
\hline Ulnar-sided pain & $\begin{array}{l}\text { Number } \\
\text { of cases }\end{array}$ & $\begin{array}{l}\text { Tournaments } \\
\text { missed }\end{array}$ & $\begin{array}{l}\text { Reduced } \\
\text { practice (weeks) }\end{array}$ \\
\hline $\begin{array}{l}\text { ECU subluxation } \\
\text { (immediate }\end{array}$ & 2 & 12 & 24 \\
$\begin{array}{l}\text { surgery) } \\
\text { ECU subluxation }\end{array}$ & 2 & 12 & 24 \\
(no surgery) & & 15 & 24 \\
ECU tenosynovitis & 8 & 0 & 0 \\
& & Mean=3.1 (0-24) & Mean=5.1 (0-12) \\
'Fat' shot pain & 2 & SD=5.1 & SD=8.1 \\
& 10 & 12 \\
Triangular & 1 & 8 & 12 \\
fibrocartilage & & 0 & 2 \\
Total ulna-sided & 16 & & \\
$\begin{array}{l}\text { 13/16 in the } \\
\text { leading wrist }\end{array}$ & & & \\
\hline ECU, Extensor carpi ulnaris. & &
\end{tabular}

Table 2 Radial wrist pain

\begin{tabular}{|c|c|c|c|}
\hline Radial-sided pain & $\begin{array}{l}\text { Number } \\
\text { of cases }\end{array}$ & $\begin{array}{l}\text { Tournaments } \\
\text { missed }\end{array}$ & $\begin{array}{l}\text { Reduced } \\
\text { practice } \\
\text { (weeks) }\end{array}$ \\
\hline De Quervain's tenosynovitis & 4 & 0 & 24 \\
\hline \multirow[t]{3}{*}{ All four in the leading wrist } & & 2 & 4 \\
\hline & & 0 & Intermitten \\
\hline & & 0 & Intermitten \\
\hline $\begin{array}{l}\text { Intersection syndrome } \\
\text { in the leading wrist }\end{array}$ & 1 & 1 & 2 \\
\hline $\begin{array}{l}\text { Total radial-sided } \\
\text { All in the leading wrist }\end{array}$ & 5 & & \\
\hline
\end{tabular}

a change in technique as a possible cause of the injury. Two golfers reported no identifiable cause.

The onset of ECU subluxation was acute in three of the four cases. These occurred as a result of an unexpected impact with a tree root or object during a full shot. Two cases underwent early surgery to repair the torn retinaculum and subsheath. One case was treated conservatively with splints and rest. Recovery time was similar in all cases. One player reported palpable ECU subluxation on the ulnar side of both wrists. This was associated with generalised laxity and, in addition, had an associated 'catch-up' midcarpal clunk. The player reported no history of acute injury and had no problems with his wrists. Ultrasound examination of the tendon showed subluxation of the tendon but no tenosynovitis or tendinosis.

Overall, 13 ulnar-sided cases experienced problems in the leading wrist ( $87 \%$ of ulnar wrist pain). Only one case of ECU tenosynovitis and one case seemed to involve a problem in TFC that occurred in the non-leading hand.

The localisation and effects of wrist problems on competition and practice are summarised in table 1 below.

\section{Radial-sided pain}

There were four golfers who were diagnosed with de Quervain's tenosynovitis in the leading hand (table 2). One case was complicated by an associated ganglion that required surgical removal. One golfer presented with an intersection syndrome in the leading wrist related to over practice at the beginning of the season.

\section{Dorsal wrist pain}

Nine golfers had ganglia on the dorsum of the wrist. Of these, six were on the leading hand and two on the non-leading hand (table 3). There were three cases of extensor tenosynovitis, one

Table 3 Dorsal wrist pain

\begin{tabular}{|c|c|c|c|}
\hline Dorsal wrist pain & $\begin{array}{l}\text { Number } \\
\text { of cases }\end{array}$ & $\begin{array}{l}\text { Tournaments } \\
\text { missed }\end{array}$ & $\begin{array}{l}\text { Reduced } \\
\text { practice } \\
\text { (weeks) }\end{array}$ \\
\hline $\begin{array}{l}\text { Ganglia (three required surgery) } \\
6 / 9 \text { in the leading wrist }\end{array}$ & 9 & $\begin{array}{l}\text { Mean=2.1 } \\
(0-10) \\
S D=1.4\end{array}$ & $\begin{array}{l}3.4(0-16) \\
S D=1.7\end{array}$ \\
\hline $\begin{array}{l}\text { Extensor synovitis } \\
2 / 3 \text { in the leading wrist }\end{array}$ & 3 & $\begin{array}{l}2 \\
0 \\
0\end{array}$ & $\begin{array}{l}6 \\
4 \\
6\end{array}$ \\
\hline $\begin{array}{l}\text { Dorsal rim impaction syndrome } \\
\text { Half in the leading wrist }\end{array}$ & 2 & $\begin{array}{l}0 \\
0\end{array}$ & $\begin{array}{l}0 \\
0\end{array}$ \\
\hline $\begin{array}{l}\text { TOTAL DORSAL-SIDED } \\
9 / 14 \text { in the leading wrist }\end{array}$ & & & \\
\hline
\end{tabular}


of which was thought to be caused by a temporary change in technique.

Two golfers had a diagnosis of dorsal rim impaction syndrome-a condition of hypertrophic radiolunate synovitis causing pain on loaded extension in the dorsal central area of the wrist. Both golfers in this study had minor symptoms and did not report any reduced practice or missed tournaments.

IV. Other problems

There were nine other wrist problems which did not fit into the above classification, were unrelated to golf or had insufficient data to reach a diagnosis. Where sufficient data were available, diagnoses included a trigger finger, osteoarthrosis, rheumatoid arthritis, a scaphoid fracture, carpal tunnel syndrome and tenosynovitis of a flexor tendon. The variety of 'other' conditions precluded any assessment of their impact on practice and play.

\section{DISCUSSION}

Our study aimed to identify the common wrist and hand injuries suffered by elite golfers and their impact on practice and tournament play. We recorded 43 injuries in 128 respondents (a rate of $31 \%$ ), similar to that reported by McCarroll and Gioe. ${ }^{5}$ The emergence of a busy professional golf schedule has led to an increase in the number of tournaments played and the number of golf-shots hit by professional golfers annually. However, golf equipment has also undergone a number of significant changes with increased shock absorption due to the use of modern materials. These changes may have offset some of the impact of increased play.

European Tour golfers play on average 100 tournament days and 50 associated practice days with around 20 weeks of practice at home. The regular travel makes continuity of medical care and specialist management almost impossible, ${ }^{6}$ which may explain why previous surveys have found that professional golfers continue to play while injured. Our study confirmed that 14 of 38 golfers $(37 \%)$ continued to play with ongoing wrist problems and supports McCarroll, ${ }^{7}$ who found that between $10 \%$ and $33 \%$ of professional golfers were playing with a variety of injuries at the time of his study.

Professional and low-handicap golfers tend to experience more wrist and hand problems than amateurs, ${ }^{25}$ which is likely to be related to technique. A highly skilled golfer will purposefully aim to 'hit through the ball' (taking a divot of turf with the club after ball contact) so that they can impart spin to the ball and thereby control its landing. This results in an increased contact force when the club hits the ball and ground, and this force is transmitted to the wrist and hand. A knowledge and understanding of the movements of the hand and wrist during the golf swing also helps to explain the injury patterns identified in our study and, as described, most hand and wrist injuries occur in the leading, nondominant limb (87\% of all wrist injuries).

The golf swing is traditionally divided into five phasesaddress, backswing, downswing, impact and follow-through. The leading, non-dominant wrist (the left wrist for right-handed golfers) begins the golf swing in a position of ulnar deviation when addressing the ball. As the club is lifted away into the backswing, this wrist moves into radial deviation until it sits maximally radially deviated at the top of the backswing (figure 1). At this point, the club changes direction to begin the downswing and the leading, non-dominant wrist returns to ulnar deviation until impact (figure 2).

The trailing, dominant wrist moves in a different path altogether, being in neutral at address before moving quickly into maximal extension during the backswing (figure 3) and

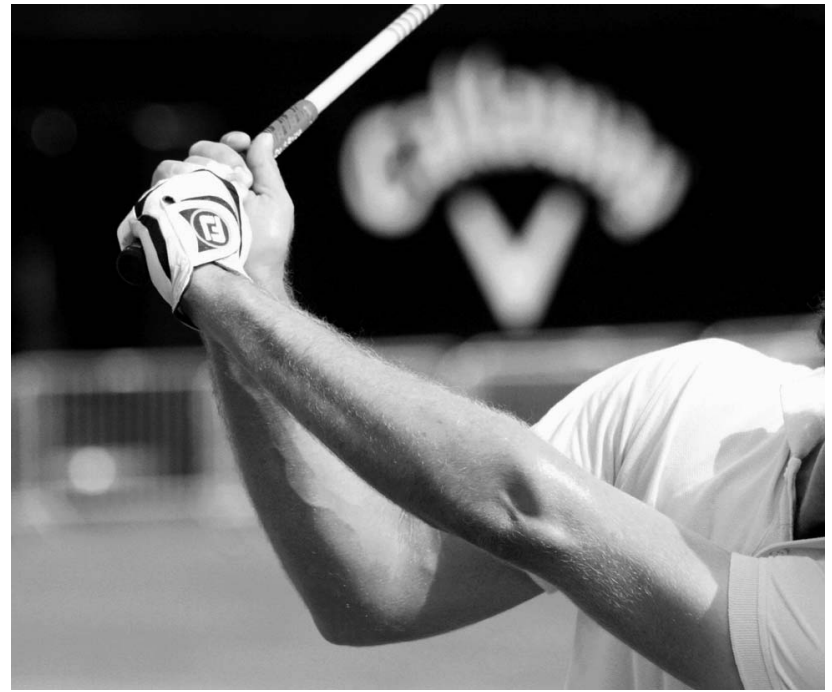

Figure 1 The leading wrist (left) is in maximal radial deviation at the top of the back swing.

only moving back into neutral (and ultimately flexion) just before impact. A more detailed description of the golf swing is provided by Theriault $e t a l^{8}$ and a biomechanical assessment of the wrist motion is provided by Chao et $a l^{9}$ and Cahalan et al. ${ }^{10}$ Several biomechanical studies have studied the load transmission across the wrist and found an increase in distal ulnar loading with progressively increasing ulnar deviation. ${ }^{11}$

An understanding of the opposing motion paths (ulnar/radial deviation for the leading, non-dominant wrist; flexion/extension for the trailing, dominant wrist) enables us to understand the mechanism of wrist and hand injuries in golf. We have demonstrated the different patterns of injury in the leading and trailing wrists. The ulnar and radial deviation of the leading, nondominant wrist predisposes to tendon problems on the radial and ulnar borders of the wrist-de Quervain's tendonitis and

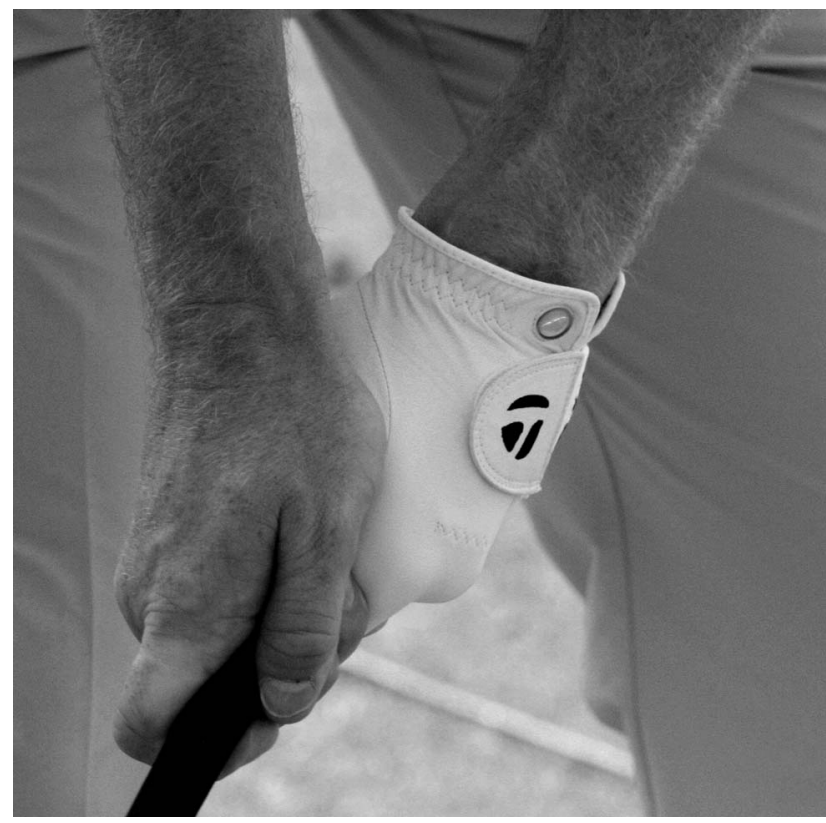

Figure 2 The leading wrist moves into neutral (shown here) and then ulnar deviation at impact. 


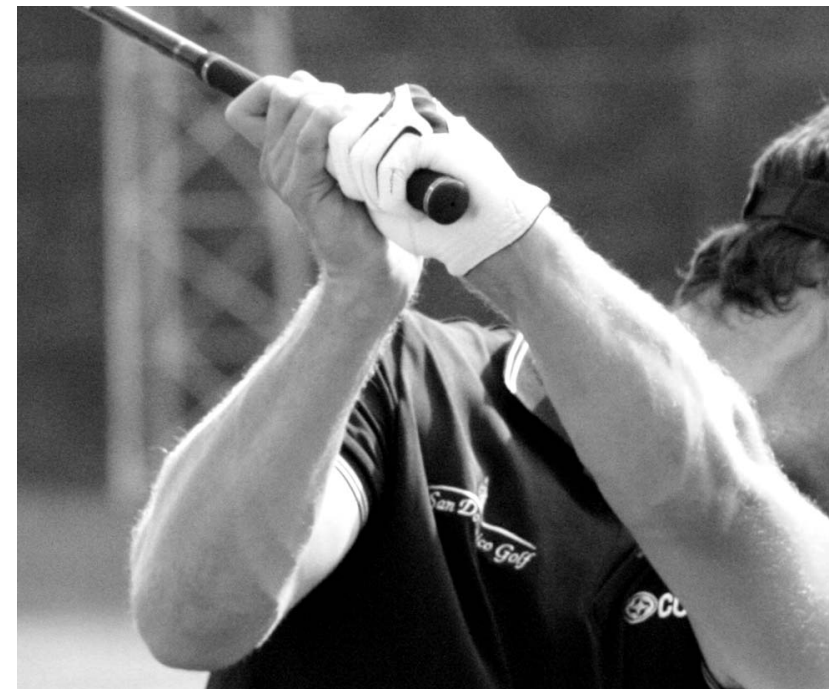

Figure 3 The trailing wrist (right) is in maximal extension at the top of the backswing.

ECU sheath. Interestingly, our golfers with de Quervain's tenosynovitis were able to control symptoms by reduced practice and with simple measures such as ice and non-steroidal anti-inflammatories.

The most serious wrist injuries in our study involved damage to the extensor retinaculum and subsheath that stabilises the ECU tendon at the base of the fifth metacarpal. Direct contact with a hard object at impact (tree root) causes sudden deceleration of the club, and the extrinsic muscles of the leading wrist need to maximally contract to maintain the wrist's static position as the decelerating club forces the wrist into radial deviation. ECU will contract on impact and the sudden and extreme forces created can rupture the structures holding the ECU tendon in place. ECU problems are consequently seen more frequently in the leading wrists of professional golfers and a rupture of the tendon sheath will give rise to instability of the ECU tendon. This can be a painful and debilitating condition, which prevents competition and practice. In our study, two golfers suffered an acute tear of the ECU retinaculum and subsheath and both underwent early surgical repair, resulting in 24 weeks of reduced practice and 12 missed tournaments. Surgical reconstruction is a successful method of treatment, ${ }^{12}$ although there is evidence to suggest that this injury responds well to non-operative treatment in elite tennis players. ${ }^{13}$ One golfer in our study was treated conservatively and had a good outcome but missed the same number of tournaments and practice as those who underwent surgery. The fourth golfer had general laxity but no symptoms associated with his subluxing ECU tendon, which appeared normal under ultrasound. In our cohort, ECU tendon subluxation following an acute, identifiable event responded well to surgery, while those with a more insidious onset did well without surgical intervention.

In our study, tenosynovitis of the ECU tendon occurred almost exclusively in the leading wrist (7 out of 8 ), as noted in other studies. ${ }^{5}$ Prolonged play on hard surfaces and mats were reported as triggers in half the cases and avoiding practice when the ground is hard or avoiding the excessive use of mats would seem sensible advice.

ECU problems occurring after hitting a 'fat' shot also produced a significant period of disability. We postulate that the sudden distraction force placed on the isometric ECU muscle and tendon may produce a tendinopathy or a partial tear within the tendon substance. The use of steroid injections to treat similar injuries in elite tennis players ${ }^{13}$ was discouraged because of the dangers of complete tendon rupture.

Rotational injuries may occur when hitting the ball out of the deep rough. The club head is trapped and twisted in long grass, producing a sudden strain on the structures that stabilise rotation of the wrist and resulting in acute, or subacute, tears of the TFCC. This appeared to be a rare injury in our study and the single case resulted in 2 weeks of reduced practice.

The study examined some simple performance characteristics to ascertain if these were affected by injury, but there were no statistically significant findings between the injured and uninjured players for either power (driving distance) or accuracy and consistency (tee to green figures).

The type, severity and impact of injuries have not been studied previously in elite professional golfers. This study recorded the prevalence of wrist and hand injuries and the effect these injuries had on tournament play and practice. The limitations of this study were similar to other retrospective questionnaire-based studies that rely on the accurate recall of events by the participants and a paucity of standardised medical documentation. Previous questionnaire-based studies in professional golf have resulted in low response rates, but this study produced a $84 \%$ response rate, which may in part be due to the study format-questionnaire, semistructured interview and personal examination.

The study group, based on players at one tournament, may be subject to selection bias. Our golfers, in progressing to the pinnacle of European golf, may self-select as a more robust group, capable of ignoring or dismissing symptoms in order to compete.

The European Tour Medical Advisory Board was established in 2008 to provide a specialist assessment, imaging and treatment service for professional golfers at the larger tournaments. ${ }^{6}$ The itinerant lifestyle of elite golfers makes it difficult for them to seek appropriate and consistent medical assistance throughout the year, and the medical support service now provided on the European Tour on the facility shown (figure 4) goes a long way to counteract this deficiency. This system also enables the collection of reliable injury data, on a prospective basis, which should lead to improved medical management of the common injuries seen in professional golf.

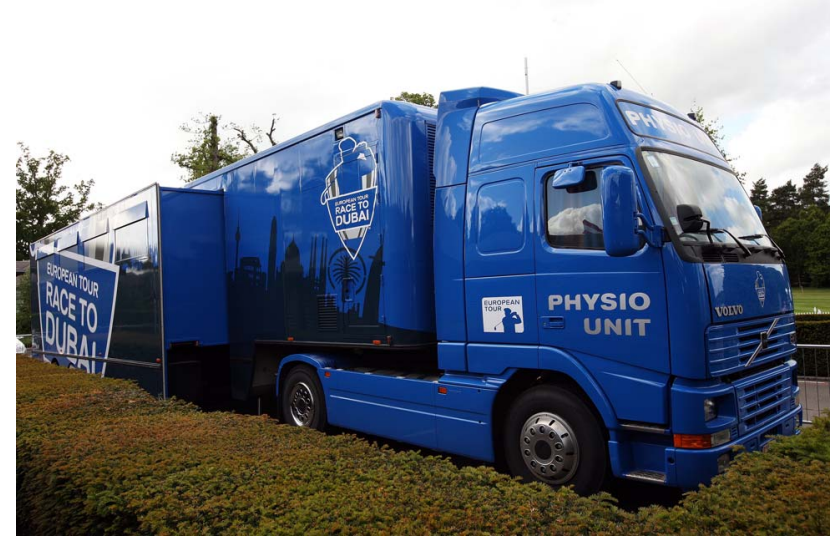

Figure 4 The roaming 'Physio' unit used on the European Tour to provide physical therapy and medical assessments at each event. 


\section{What are the new findings?}

- Wrist injuries in professional golf can be performance-limiting and some can lead to a prolonged absence.

- The leading wrist is most vulnerable to injury.

- Ulnar-sided wrist symptoms are more common than radial-sided symptoms.

- The optimal management of extensor carpi ulnaris subluxation may not always be surgical.

\section{How might it impact on clinical practice in the near} future?

- Complete functional assessment will be required to diagnose wrist problems in golfers.

- Many conditions can be managed by a change in the amount of practice and/or change in technique.

- Reduction of practice and avoiding playing off mats may allow golfers to control overuse symptoms in the wrist.

Acknowledgements The authors thank the members of the European Tour Advisory Board, as well as the Physiotherapy and Sports Medical team of the European Tour for their comments, support and help with the study.

Contributors $\mathrm{RH}$ and $\mathrm{PO}$ conceived the idea, which was then designed by DC and $\mathrm{RH}$ and together with $\mathrm{DC}$ and $\mathrm{PO}$ was carried out; $\mathrm{RH}$ and $\mathrm{DC}$ carried out the data analysis. $\mathrm{RH}$ and $\mathrm{DC}$ not only interpreted the results but also cowrote the paper with revisions being done by PO before final approval was given by all three authors.

Funding Expenses were paid by the European Tour.

Competing interests None.
Ethics approval The study was approved by the Centre for Sport and Exercise Science, Sheffield Hallam University.

Provenance and peer review Not commissioned; externally peer reviewed.

Open Access This is an Open Access article distributed in accordance with the Creative Commons Attribution Non Commercial (CC BY-NC 3.0) license, which permits others to distribute, remix, adapt, build upon this work non-commercially, and license their derivative works on different terms, provided the original work is properly cited and the use is non-commercial. See: http://creativecommons.org/ licenses/by-nc/3.0/

\section{REFERENCES}

1 The Global Golf Report 2003 Golf Research Group, 4028 Amherst, Dallas.

2 Gosheger G, Liem D, Ludwig K, et al. Injuries and overuse syndromes in golf. Am J Sports Med 2003;31:438-43.

3 McCarroll JR, Retting AC, Shelbourne KD. Injuries in the amateur golfer. Physician Sportsmed 1990;18:122-6.

4 Batt ME. A survey of golf injuries in amateur golfers. Br I Sports Med 1992;26:63-5.

5 McCarroll JR, Gioe TJ. Professional golfers and the price they pay. Physician Sportsmed 1982;10:64-70.

6 O' Connor PJ, Hawkes R. Imaging the elite golfer. Skeletal Radiol 2012;42:607-9.

7 Reid I. The 2006 Golf Participation in Canada Report. On behalf of the Royal Canadian Golf Association.

8 Theriault $\mathrm{G}$, Lacoste $\mathrm{E}$, Gaboury $\mathrm{M}$, et al. Golf injury characteristics: a survey of 528 golfers [abstract]. Med Sci Sports Exerc 1996;28:S65.

9 Chao EYS, Tamai K, Cahalan TD, et al. Biomechanics of the golf swing as related to club handle design. Biomech Sports 1987;DE-vol 13/BED-vol 6:107-11.

10 Cahalan TD, Cooney WP, Tamai K, et al. Biomechanics of the golf swing in players with pathologic conditions of the forearm, wrist and hand. Am I Sports Med 1991;19:288-93.

11 Af Ekenstam FW, Palmer AK, Glisson RR. The load on the radius and ulna in different positions of the wrist and forearm. A cadaver study. Acta Orthop Scand 1984;55:363-5.

12 Rowland SA. Acute traumatic subluxation of the extensor carpi ulnaris tendon at the wrist. J Hand Surg 1986;11A:809-11.

13 Montalvan B, Parier J, Brasseur JL, et al. Extensor carpi ulnaris injuries in tennis players: a study of 28 cases. Br I Sports Med 2006;40:424-9. 